\title{
Dot Locations Total Score
}

National Cancer Institute

\section{Source}

National Cancer Institute. Dot Locations Total Score. NCI Thesaurus. Code C120337.

The total score from the Children's Memory Scale Dot Locations Short Delay and Dot Locations Long Delay. 